REVISED

SHORT COMMUNICATION

\title{
IL-33 stimulates expression of the GPR84 (EX33) fatty acid receptor gene and of cytokine and chemokine genes in human adipocytes
}

Mohamed S. Zaibi ${ }^{a}$, Małgorzata A. Kępczyńska ${ }^{a}$, Parvathy Harikumar ${ }^{a}$, Suliman Y. Alomar ${ }^{b}$ and Paul Trayhurn ${ }^{\mathrm{a}, \mathrm{b}, \mathrm{c}, *}$

${ }^{a}$ Clore Laboratory, University of Buckingham, Hunter Street, Buckingham MK18 1EG, United Kingdom, 'Zoology Department, College of Science, King Saud University, Riyadh, 11451 Saudi Arabia, and 'Obesity Biology Unit, University of Liverpool, Liverpool L69 3GA, United Kingdom

RUNNING TITLE: IL-33 stimulates gene expression in human adipocytes

Correspondence should be addressed to:

Professor Paul Trayhurn, FRSE

Clore Laboratory

University of Buckingham

Hunter Street

Buckingham MK18 1EG

UK

Email: $\quad$ p.trayhurn@liverpool.ac.uk

Fax: $\quad$ +441280820135 


\begin{abstract}
Expression of GPCR fatty acid sensor/receptor genes in adipocytes is modulated by inflammatory mediators, particularly IL-1 $\beta$. In this study we examined whether the IL-1 gene superfamily member, IL-33, also regulates expression of the fatty acid receptor genes in adipocytes. Human fat cells, differentiated from preadipocytes, were incubated with IL-33 at three different dose levels for 3 or $24 \mathrm{~h}$ and mRNA measured by qPCR. Treatment with IL-33 induced a dose-dependent increase in GPR84 mRNA at $3 \mathrm{~h}$, the level with the highest dose being 13.7-fold greater than in controls. Stimulation of GPR84 expression was transitory; the mRNA level was not elevated at $24 \mathrm{~h}$. In contrast to GPR84, IL-33 had no effect on GPR120 expression. IL-33 markedly stimulated expression of the IL1B, CCL2, IL6, CXCL2 and CSF3 genes, but there was no effect on $A D I P O Q$ expression. The largest effect was on CSF3, the mRNA level of which increased 183-fold over controls at $3 \mathrm{~h}$ with the highest dose of IL-33; there was a parallel increase in the secretion of G-CSF protein into the medium. It is concluded that in human adipocytes IL-33, which is synthesised in adipose tissue, has a strong stimulatory effect on the expression of cytokine and chemokine genes, particularly CSF3, and on the expression of GPR84, a pro-inflammatory fatty acid receptor.
\end{abstract}

\title{
Keywords:
}

Adipocyte

Adipose tissue

GPR84

Inflammation

Interleukin-33 


\section{Introduction}

Several G-protein coupled receptors act as sensors/receptors for fatty acids [1-2]. GPR120 (or FFAR4), is a receptor for $n-3$ polyunsaturated fatty acids, and has been linked to the antiinflammatory action of these lipids [2-3]. The primary ligands for GPR41 (FFAR3) and GPR43 (FFAR2) are short chain fatty acids, while GPR40 (FFAR1) is activated by medium and long chain saturated and mono-unsaturated fatty acids [1-2]. GPR84 (EX33), a pro-inflammatory receptor, is also activated by medium chain fatty acids [4-5]. Each of these GPCRs has a distinct tissue distribution, with GPR120 being strongly expressed in both adipocytes and macrophages (M1 and M2) in white adipose tissue, where it promotes adipogenesis [6] in addition to insulin sensitising and anti-inflammatory actions [2-3]. Adipocytes also express GPR84, and at least in the case of human fat cells GPR40, GPR41 and GPR43, albeit at low levels [7].

Recent studies have shown that the expression of GPR84, GPR41 and GPR120 is powerfully and differentially modulated by inflammatory mediators. Macrophage-conditioned medium, lipopolysaccharide, TNF $\alpha$ and IL-1 $\beta$ have each been shown to strongly stimulate GPR84 expression [4, 7-9]. In contrast, GPR120 expression is markedly reduced by these agents [7-8]. IL-1 $\beta$ induces a particularly strong stimulation of GPR84 expression in human adipocytes and the expression of GPR41 is also increased [7]. The IL-1 superfamily of cytokines comprises other pro-inflammatory agonists in addition to IL-1 $\beta$, including IL-18 and IL-33 [10], both of which are produced by human white adipocytes [10-11]. However, the main source of IL-33 in human adipose tissue appears to be endothelial cells [12]. IL-33 has multiple effects in inflammation and immunity, involving the stimulation of regulatory $\mathrm{T}\left(\mathrm{T}_{\text {reg }}\right)$ cells and the production of Th2 cytokines and chemokines such as IL-5, IL-6 and MCP-1, including in adipose tissue [13].

In view of the link between inflammation and the production of GPCR fatty acid receptors in adipocytes, we have examined whether IL-33 modulates the expression of key fatty acid receptor genes in human adipocytes, and of cytokine and chemokine genes.

\section{Materials and methods}

\subsection{Adipocyte cell culture}

Human preadipocytes, isolated from subcutaneous adipose tissue, and proprietary cell culture media were purchased from PromoCell (Germany; Catalogue \#C-12730, Lots \#419Z023). The cells were plated into 12 -well plates $\left(5,000 \mathrm{cells} / \mathrm{cm}^{2}\right)$, cultured to confluence, differentiated into adipocytes and then further cultured in nutrition medium (changed every 2-3 days) for up to 14 days, as previously [14]. The nutrition medium contained 3\% foetal calf serum, dexamethasone 
(400 $\mathrm{ng} / \mathrm{ml}$ ) and insulin $(0.5 \mu \mathrm{g} / \mathrm{ml})$. Differentiated adipocytes, characterised by fat droplets, were used at 12-14 days after differentiation was induced.

The adipocytes were divided into four groups which were incubated with either 0 (controls), 5, 25 or $100 \mathrm{ng} / \mathrm{ml}$ of recombinant IL-33 (Sigma, UK) for 3 or $24 \mathrm{~h}$. The dose levels were based on previous studies [13]. Following the incubation period, the medium was aspirated and stored at $-20^{\circ} \mathrm{C}$, and the cells washed and frozen in TRI Reagent (Sigma) prior to storage at $-80^{\circ} \mathrm{C}$. Six individual sets of adipocytes were taken for each group.

\subsection{RNA extraction and real-time PCR}

The adipocytes were thawed and homogenised in the TRI Reagent in which they were stored, and RNA extracted using an RNeasy Micro Kit (Qiagen, UK). The purity of the extracted RNA was close to 2.0 (260/280 and 260/230 ratios by NanoDrop 1000, Wilmington, USA). The RNA was DNAse-treated with a TURBO-DNA-free ${ }^{\mathrm{TM}}$ kit (Ambion, Life Technologies, USA) and $2 \mu \mathrm{g}$ reverse transcribed using Taqman ${ }^{\circledR}$ reverse transcription reagents (Applied Biosystems, UK). cDNA (40-80 ng) was taken for real-time PCR which was performed in triplicates using a Gene Expression Master Mix and TaqMan ${ }^{\circledR}$ Gene Assays consisting of specific Taqman ${ }^{\circledR}$ probes (Applied Biosystems). The following human gene probes were employed: GPR41 (Hs02519193_g1), GPR84 (Hs01874713_s1), GPR120 (Hs00699184_m1), CCL2 (Hs00234140_m1), IL1B (Hs01555410_m1), IL6 (Hs00985639_m1), ADIPOQ (Hs00605917_m1), CSF3 (Hs00738432_gl), CXCL2 (Hs00601975). ACTB (Hs99999903_m1) was the reference gene. PCR reactions were arranged in duplex format with the FAM-labelled Taqman $^{\circledR}$ probe for each gene mixed with the VIC-labelled Taqman ${ }^{\circledR}$ probe for ACTB.

PCR amplification was performed with an ABI real-time PCR detection system (ABI StepOneplus, Applied Biosystems) with two-step thermal cycling: $95^{\circ} \mathrm{C}$ for $10 \mathrm{~min}$, followed by 40 cycles of $95^{\circ} \mathrm{C}$ for $15 \mathrm{sec}$ and $60^{\circ} \mathrm{C}$ for $1 \mathrm{~min}$. Data were analysed by the comparative $2^{-\Delta \Delta} \mathrm{Ct}$ method, as previously [7, 14] and expressed as fold-changes in the target gene (normalized to $A C T B$ ) in adipocytes treated with IL-33 in relation to expression in the control cells (control cells =1).

\subsection{Protein immunoassays}

The concentration of IL-6 and G-CSF in the culture medium, which was centrifuged to remove any cell debris, was measured using sensitive MSD immunoassays (Meso Scale Discovery, USA). Plates were pre-coated with antibodies on discrete spots and the assay performed according to the manufacturer's instructions, as previously [7, 14]; data were analysed using Meso Scale software. The minimum level of detection was $0.06 \mathrm{pg} / \mathrm{ml}$ for IL-6 (interlot CV <20 \%) and 1.5 $\mathrm{pg} / \mathrm{ml}$ for CSF3 (interlot CV <18\%). 


\subsection{Statistical analysis}

The statistical significance of differences between groups was assessed by one-way ANOVA with a Bonferroni post-test (for selected groups) or with Student's unpaired $t$ test. A value of $P<0.05$ was taken as statistically significant.

\section{Results}

Human adipocytes, differentiated from fibroblastic preadipocytes in culture, were incubated with IL-33 for either 3 or $24 \mathrm{~h}$ to examine acute and prolonged responses to the cytokine. Low, medium and high concentrations of IL-33 were employed. IL-33 had no significant effect on GPR120 mRNA level at either 3 or $24 \mathrm{~h}$, except for a small, but statistically significant, reduction for the middle concentration of the cytokine at the shorter time point (Fig 1b). There was also no effect of IL-33 on GPR41 mRNA level at $24 \mathrm{~h}$; a small, dose-dependent, increase was evident at $3 \mathrm{~h}$, the increase being statistically significant with the highest dose (Fig 1c). In contrast, IL-33 induced a marked, dose-dependent increase in GPR84 mRNA at $3 \mathrm{~h}$, the level with the high dose being 13.7-fold greater than in controls (Fig 1a). This effect was, however, transitory; there was no significant change in GPR84 mRNA at $24 \mathrm{~h}$ (Fig 1a).

To assess the effects of IL-33 on the expression of classical inflammation-related genes, the mRNA level of a group of cytokine and chemokines was examined. IL-33 induced a marked, dose-dependent increase in mRNA of the ILB, IL6, CCL2, CXCL2 and CSF3 genes at $3 \mathrm{~h}$ (Fig 2a-e). With the highest dose of IL-33, there were 3.0-, 11.7-, 15.2- and 15.6-fold increases in mRNA level of the CCL2, IL6, CXCL2 and ILB genes, respectively. CSF3 exhibited a very substantial response to IL-33, the mRNA level with the highest dose of the cytokine being 183fold higher than in the controls (Fig 2e).

As with GPR84, these responses to IL-33 were transitory; there was no effect of IL-33 on IL-1 $\beta$ mRNA at $24 \mathrm{~h}$ (Fig 2a), and there was actually a small reduction in CCL2 mRNA with the low and medium doses of the cytokine (Fig 2c). CSF3, IL-6 and CXCL2 mRNA levels were each elevated at $24 \mathrm{~h}$ with the highest dose of IL-33 (3.9-, 2.5- and 3.3-fold, respectively); however, for CSF3, the increase was substantially lower than the 183-fold increase at $3 \mathrm{~h}$.

In contrast to the other adipokine genes, expression of $A D I P O Q$, which encodes the key adipocyte hormone adiponectin, was not modified by IL-33, the mRNA level being unchanged at both 3 and $24 \mathrm{~h}$ with each dose of the cytokine (Fig 2f). IL18 expression was also unaltered (results not shown).

To determine whether the changes in cytokine and chemokine gene expression were reflected by similar changes in secretion of the encoded protein, the effect of IL-33 on the 
release of IL-6 and G-CSF was examined. Treatment with IL-33 resulted in a dose-dependent increase in the amount of the two adipokines in the culture medium at both 3 and $24 \mathrm{~h}$ (Fig $2 \mathrm{~g}$ and $2 \mathrm{~h}$ ). The amount of both proteins was greater at $24 \mathrm{~h}$ than at $3 \mathrm{~h}$, reflecting the delay between increases in mRNA level and release of the protein product. At $24 \mathrm{~h}$, with the highest dose of IL-33, the amount of IL-6 was 7.9-fold greater than in the controls (4.7-fold at $3 \mathrm{~h}$ ) and 23.9-fold higher (4.6-fold at $3 \mathrm{~h}$ ) in the case of G-CSF.

\section{Discussion}

This study demonstrates that expression of the GPR84 fatty acid receptor/sensor gene in human adipocytes is strongly and acutely stimulated by IL-33. This parallels the stimulatory effect of IL$1 \beta$ and $\mathrm{TNF} \alpha$, as well as other mediators, on the expression of this gene in fat cells [4, 7-9]. GPR84 is considered a pro-inflammatory receptor, its activation amplifying the production of IL-8 and IL-12 p40 in polymorphonuclear leukocytes and of TNF $\alpha$ by macrophages [5]. Thus IL-33 may contribute to the inflammatory response in adipose tissue in part through increased production of GPR84.

IL-33 did not have a suppressive effect on GPR120 expression, in contrast to TNF $\alpha$ and IL-1 [7-8]. The insulin sensitising and anti-inflammatory actions of GPR120, which is a receptor for n-3 polyunsaturated fatty acids [2-3], is unlikely to be modified by IL-33 contrary to what has been projected with IL-1 $\beta$ and TNF $\alpha$ [7]. The intracellular signalling pathways linked to the IL33 receptor, ST2 (and its co-receptor IL-1 receptor accessory protein) [15], which are expressed in human adipocytes [11], would appear to be implicated in the modulation of the transcription of the GPR84 gene, but not GPR120. It is noted that while 3 and $24 \mathrm{~h}$ time-points were employed, reflecting potential acute and sustained effects of IL-33, the possibility cannot be excluded that some changes might occur at intermediate times, but if so these are likely to be limited.

IL-33 had marked effects on the inflammatory response in human adipocytes beyond GPR84, with a substantial stimulation of the expression of a selected group of cytokine and chemokine genes. Expression of IL1B, a co-member of the IL-1 superfamily, was strongly upregulated by IL-33, as was IL6 and CXCL2 (encoding MCP-1) and CSF3. Stimulation of MCP-1, and IL- 6 from the stromovascular fraction of murine adipose tissue by IL-33 has been noted previously [13]. Stimulation of CSF3 expression was particularly marked in the present study, and this was accompanied by a major increase in the secretion of G-CSF into the medium. CSF3 expression is also strongly up-regulated in human adipocytes by IL-1 $\beta$ [14]. The substantial 
increase in G-CSF production may be linked to neutrophil recruitment and function in adipose tissue, as well as a potential neutrophic/neuroprotective role in inflammation in the tissue.

In contrast to the other adipokine genes examined, IL-33 had no effect on the expression of $A D I P O Q$. Since adiponectin, the adipocyte hormone encoded by $A D I P O Q$, has antiinflammatory and insulin sensitising functions [see 7], IL-33 does not compromise the production of a factor with these actions, unlike IL-1 $\beta$ and TNF $\alpha$ which inhibit $A D I P O Q$ expression [7, 14]. As with GPR120, the possibility cannot be excluded of some small response to IL-33 at time-points intermediate to 3 and $24 \mathrm{~h}$.

There are multiple potential sources of IL-33 within adipose tissue, since the IL 33 gene is expressed in adipocytes, macrophages and endothelial cells [12]. As such, the cytokine may have both autocrine and paracrine actions in the tissue. IL33 expression is elevated in adipose tissue of obese humans where it is suggested that it may contribute to inflammation in obesity [12], However, a protective effect of IL-3 has also been proposed [13, 16]; IL-33 reduces the inflammatory response in adipose tissue in obese mice through polarising macrophages to the M2 phenotype as well as reversing the overall recruitment of macrophages and the accumulation of pro-inflammatory cytokines $[13,16]$. These changes may counter the direct pro-inflammatory effects of IL-33 on adipocytes.

\subsection{Conclusions}

IL-33 has selective actions on GPR fatty acid receptor gene expression in human adipocytes, stimulating expression of the pro-inflammatory receptor GPR84. IL-33 also has extensive effects on the production of key cytokines and chemokines in human adipocytes, with a powerful stimulatory action on the expression of CSF3 and the secretion of its protein product G-CSF. IL-33 may be a significant modulator of the inflammatory response in adipose tissue.

\section{Acknowledgements}

We are grateful to the Distinguished Scientist Fellowship Programme, King Saud University, for financial support of this work; the sponsor had no involvement in any aspect of the study.

\section{Conflicts of interest.}

The authors declare that they have no competing interests. 


\section{References}

[1] G. Milligan, T. Ulven, H. Murdoch, B.D. Hudson, G-protein-coupled receptors for free fatty acids: nutritional and therapeutic targets, Br. J. Nutr. 111 (2014) Suppl 1, S3-S7.

[2] T. Ulven, E. Christiansen, Dietary fatty acids and their potential for controlling metabolic disease through activation of FFA4/GPR120, Ann. Rev Nutr. 35 (2015) 239-263.

[3] D.Y. Oh, S. Talukdar, E.J. Bae, T. Imamura, H. Morinaga, W. Fan, et al., GPR120 is an omega-3 fatty acid receptor mediating potent anti-inflammatory and insulin-sensitizing effects, Cell 142 (2010) 687-698.

[4] J. Wang, X. Wu, N. Simonavicius, H. Tian, L. Ling, Medium-chain fatty acids as ligands for orphan G protein-coupled receptor GPR84, J. Biol. Chem. 281 (2006) 34457-34464.

[5] M. Suzuki, S. Takaishi, M. Nagasaki, Y. Onozawa, I. Iino, H. Maeda, et al., Medium-chain fatty acid-sensing receptor, GPR84, is a proinflammatory receptor, J. Biol. Chem. 288 (2013) 10684-10691.

[6] T. Song, Y. Zhou, J. Peng, Y.-X. Tao, Y. Yang, T. Xu, et al., GPR120 promotes adipogenesis through intracellular calcium and extracellular signal-regulated kinase $1 / 2$ signal pathway, Mol. Cell. Endocrinol. 434 (2016) 1-13.

[7] L. Muredda, M.A. Kepczynska, M.S. Zaibi, S.Y. Alomar, P. Trayhurn, IL-1 $\beta$ and TNF $\alpha$ inhibit GPR120 (FFAR4) and stimulate GPR84 (EX33) and GPR41 (FFAR3) fatty acid receptor expression in human adipocytes: implications for the anti-inflammatory action of n-3 fatty acids, Arch. Physiol. Biochem. (2018) in press.

[8] P. Trayhurn, G. Denyer, Mining microarray datasets in nutrition: expression of the GPR120 (n-3 fatty acid receptor/sensor) gene is down-regulated in human adipocytes by macrophage secretions, J. Nutr. Sci. 1 (2012) e3.

[9] H. Nagasaki, T. Kondo, M. Fuchigami, H. Hashimoto, Y. Sugimura, N. Ozaki, et al., Inflammatory changes in adipose tissue enhance expression of GPR84, a medium-chain fatty acid receptor: TNF $\alpha$ enhances GPR84 expression in adipocytes, FEBS Lett. 586 (2012) 368-372.

[10] D.B. Ballak, R. Stienstra, C.J. Tack, C.A. Dinarello, J.A. van Diepen, IL-1 family members in the pathogenesis and treatment of metabolic disease: Focus on adipose tissue inflammation and insulin resistance, Cytokine 75 (2015) 280-290.

[11] I.S. Wood, B. Wang, P. Trayhurn, IL-33, a recently identified interleukin-1 gene family member, is expressed in human adipocytes, Biochem. Biophys. Res. Comm. 384 (2009) 105-109. 
[12] M. Zeyda, B. Wernly, S. Demyanets, C. Kaun, M. Hammerle, B. Hantusch, et al., Severe obesity increases adipose tissue expression of interleukin-33 and its receptor ST2, both predominantly detectable in endothelial cells of human adipose tissue, Int. J. Obesity 37 (2013) 658-665.

[13] A.M. Miller, D.L. Asquith, A.J. Hueber, L.A. Anderson, W.M. Holmes, A.N. McKenzie, et al., Interleukin-33 induces protective effects in adipose tissue inflammation during obesity in mice, Circulation Res. 107 (2010) 650-658.

[14] S.Y. Alomar, M.S. Zaibi, M.A. Kepczynska, A. Gentili, A. Alkhuriji, L. Mansour, et al., PCR array and protein array studies demonstrate that IL-1 $\beta$ (interleukin-1 $\beta$ ) stimulates the expression and secretion of multiple cytokines and chemokines in human adipocytes, Arch. Physiol. Biochem. 121 (2015) 187-193.

[15] F.Y. Liew, J.P. Girard, H.R. Turnquist, Interleukin-33 in health and disease, Nat. Rev. Immunol. 16 (2016) 676-689.

[16] J.M. Han, D. Wu, H.C. Denroche, Y. Yao, C.B. Verchere, M.K. Levings, IL-33 reverses an obesity-induced deficit in visceral adipose tissue ST2 + T regulatory cells and ameliorates adipose tissue inflammation and insulin resistance, J. Immunol. 194 (2015) 4777-4783. 


\section{Legends to Figures}

Fig. 1. Effect of IL-33 on (a) GPR84, (b) GPR120, and (c) GPR41 gene expression in human adipocytes. The adipocytes were incubated with IL-33 (5, 20, or $100 \mathrm{ng} / \mathrm{ml})$ for either 3 or $24 \mathrm{~h}$. The results, which are expressed as fold-changes in mRNA level in cells treated with IL-33 relative to the respective control cells (no IL-33), are means \pm SE (bars) for 4-6 sets of adipocytes. $* P<0.05,{ }^{*} * * P<0.001$ compared with the control cells at the same time point.

Fig. 2. Effect of IL-33 on cytokine and chemokine gene expression (a-f) and protein secretion $(\mathrm{g}, \mathrm{h})$ in human adipocytes. The adipocytes were incubated with IL-33 (5, 20, or $100 \mathrm{ng} / \mathrm{ml})$ for either 3 or 24 h. (a) IL1B, (b) CXCL2, (c) CCL2, (d) IL6, (e) CSF3, and (f) ADIPOQ gene expression. The gene expression results are fold-changes in mRNA level in cells treated with IL33 relative to the respective control cells (no IL-33). The amount of protein was measured in the medium for IL-6 (g) and G-CSF (h). All results are means \pm SE (bars) for 4-6 sets of adipocytes. ${ }^{*} P<0.05,{ }^{*} P<0.01,{ }^{* * *} P<0.001$ compared with the control cells at the same time point. 
Click here to download high resolution image

Figure 1

(single column)

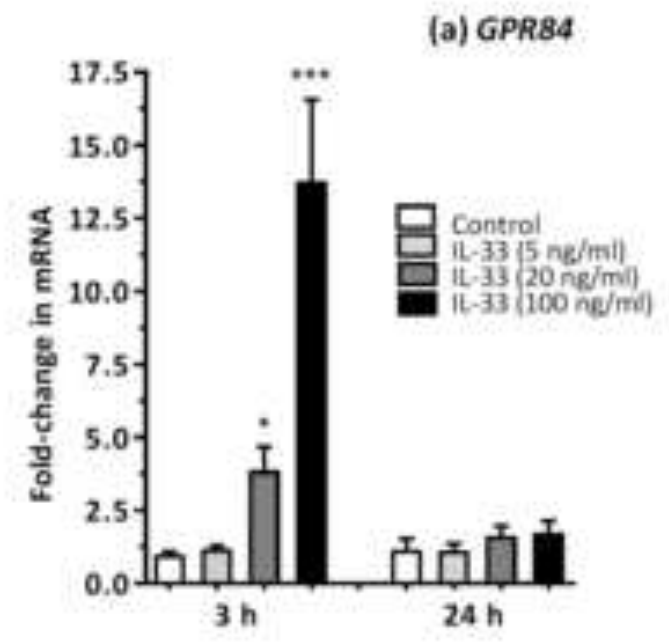

(b) GPR120
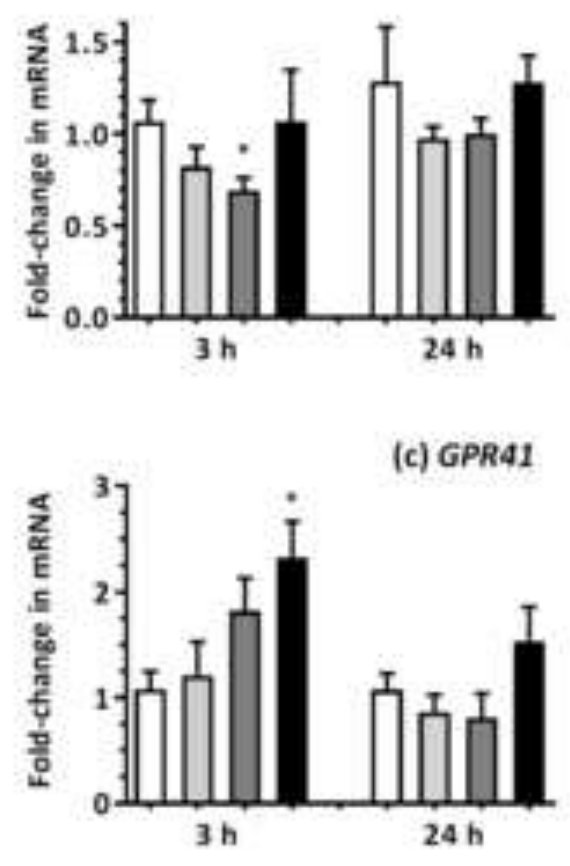
Figure 2

Click here to download high resolution image

Figure 2.

(2 column)

(a) $14.1 \mathrm{~B}$
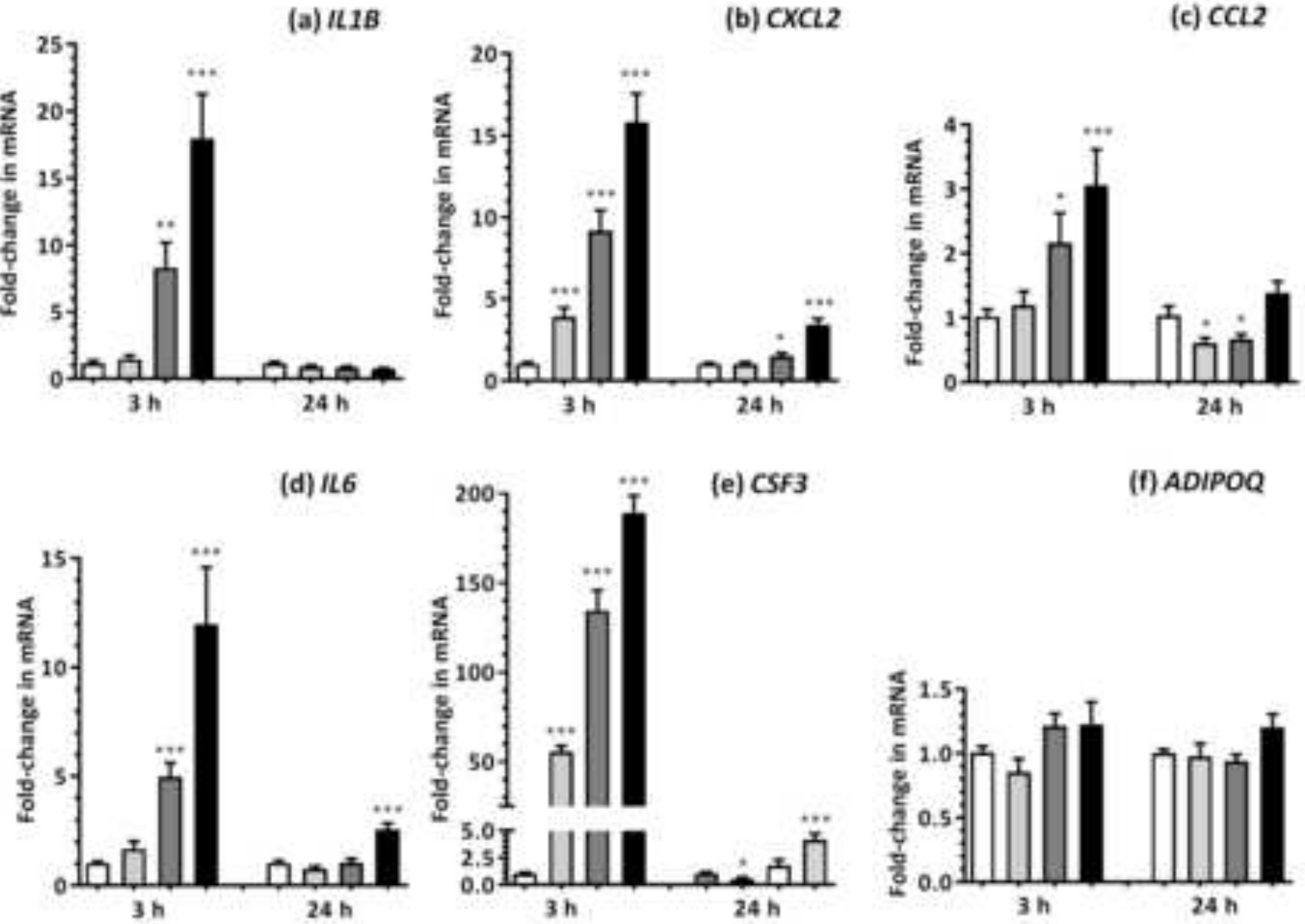

(g) IL-6 protein

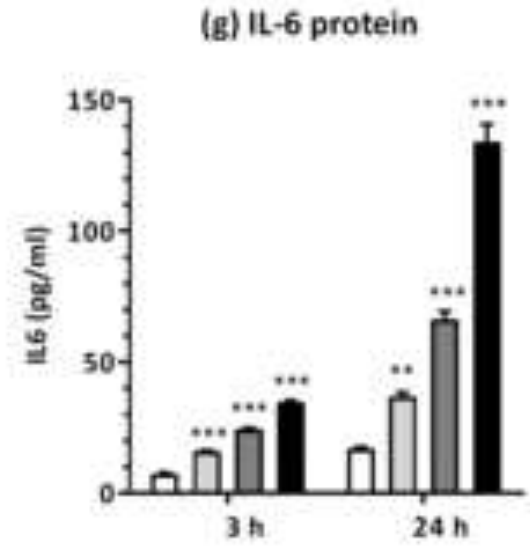

(h) G-CSF protein

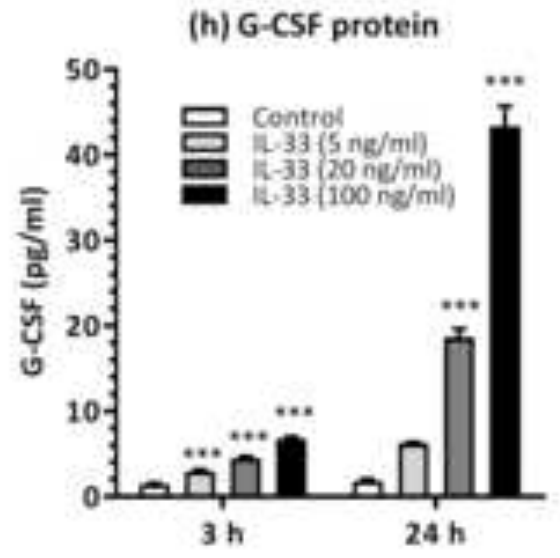

(c) $\mathrm{CCL} 2$

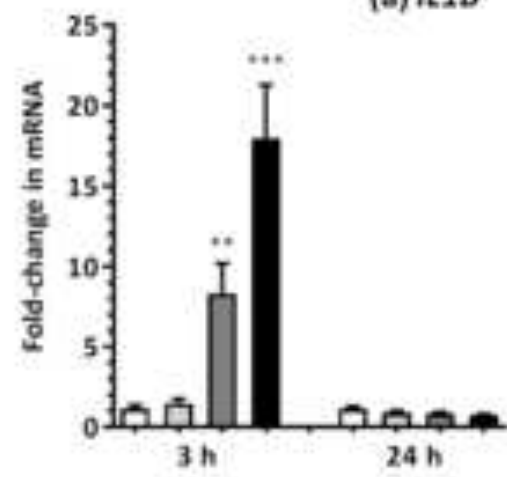

(f) $A D I P O Q$ 
Subject: CYTO-18-226R1 - Final Decision

From: Cytokine <eesserver@eesmail.elsevier.com>

Date: 10/05/2018 14:24

To: Paul Trayhurn <paul.trayhurn@buckingham.ac.uk>

Ms. No.: CYTO-18-226R1

Title: IL-33 stimulates expression of the GPR84 (EX33) fatty acid receptor gene and of cytokine and chemokine genes in human adipocytes

Corresponding Author: Professor P Trayhurn

Authors: Mohamed Zaibi; Małgorzata A Kępczyńska; Parvathy Harikumar; Suliman Y Alomar;

Dear Professor Trayhurn,

I am pleased to inform you that your manuscript referenced above has been accepted for publication in Cytokine.

Your accepted manuscript will now be transferred to our production department and work will begin on creation of the proof. If we need any additional information to create the proof, we will let you know. If not, you will be contacted again in the next few days with a request to approve the proof and to complete a number of online forms that are required for publication.

Cytokine is an official journal of the International Cytokine and Interferon Society whose principal function is to hold a major conference annually at different sites around the world. If you are not already a member of the International Cytokine and Interferon Society and wish to know more about its activities, please visit http://www.cytokinesociety.org

When your paper is published on ScienceDirect, you want to make sure it gets the attention it deserves. To help you get your message across, Elsevier has developed a new, free service called AudioSlides: brief, webcast-style presentations that are shown (publicly available) next to your published article. This format gives you the opportunity to explain your research in your own words and attract interest. You will receive an invitation email to create an AudioSlides presentation shortly. For more information and examples, please visit http://www.elsevier.com/audioslides.

Thank you for sending the results of your interesting work to Cytokine. I look forward to receiving additional papers from you in the future.

With kind regards,

Cytokine

Our new self-help site at http://help.elsevier.com/app/answers/list/p/7923 describes a range of EES topics, answers frequently asked questions, and provides interactive EES tutorials for authors, editors and reviewers. 
Creative Commons License

(C) <2018>. This manuscript version is made available under the CC-BY-NC-ND 4.0 license http://creativecommons.org/licenses/by-nc-nd/4.0/ $\nearrow$ 